\title{
Assessing sustainability performance of built projects - A building process approach
}

\author{
Grace K C Ding \\ School of the Built Environment \\ University of Technology Sydney \\ PO Box 123, Broadway, \\ NSW 2007, Australia \\ Email: grace.ding@uts.edu.au
}

\author{
L Y Shen \\ Department of Building and Real Estate \\ The Hong Kong Polytechnic University \\ Hung Hom, Kowloon, Hong Kong \\ Email: bsshen@polyu.edu.hk
}

Biographical notes: Grace K C Ding is a senior academic in the School of Built Environment at the University of Technology Sydney, Australia. Her research areas include sustainable construction, sustainable building performance, life cycle energy analysis and has been published widely in journal articles, books and international conferences.

LY Shen is the Professor and Associate Head of the Department of Building and Real Estate at the Hong Kong Polytechnic University. He is also the Editor of the International Journal of Construction Management. Professor Shen is widely published in the areas of risk management for construction, sustainable construction, and competitive strategy for construction and IT-supported system for the assessment of contractor competitiveness.

\begin{abstract}
Whilst construction activities have been contributing to the development of modern societies, they are also contributing negative effects to the environment. Traditional project appraisal techniques centre on assessing a project's economic outcomes. However, it is important that project feasibility also takes sustainability into account, for which economic benefits, environmental and social impacts are the major determinants. It appears that environmental impact is insufficiently addressed in the current framework of project feasibility studies. Most of the existing environmental performance assessment approaches focus on the overall performance to reflect sustainability of built projects. However the impacts caused by construction activities on the environment occur throughout a project's life cycle which may be different at different stages. Similarly, the economic benefits and social impacts from implementing a construction project may also be different in different project stages. This paper presents the model of the sustainable development value (SDV) which integrates sustainability assessment into the building process. SDV measures the significance of the concerned project to the attainment of sustainable development value at different stages of a building life cycle and the SDV at each stage will be amalgamated into the model of sustainable development ability (SDA). SDA is used as a prototype to demonstrate the extent of sustainable performance to aid decision making. This paper presents the methodological framework of SDV and SDA, and the implementation was demonstrated using a case study.
\end{abstract}

Key words: sustainable construction, sustainable development value, sustainable development ability, building process 


\section{Introduction}

The building sector contributes to the economic and social advancement of society, enhancing the standard of living. On one hand it employs over 111 million people worldwide and contributes approximately 5 to $15 \%$ of the global domestic product. On the other hand it also accounts for the world's resource depletion and environmental degradation. It accounts for $20 \%$ of the water effluents, 30 to $40 \%$ of the solid waste generation and $\mathrm{CO}_{2}$ emission, $20 \%$ water, 30\% raw materials, and 25 to $40 \%$ energy (UNEP SBCI, 2008).

Project development in the building sector may readily contribute to the objective of sustainable development by minimizing their adverse effects, by minimizing resource and energy consumption, maximizing reuse and recycling, stressing clean production, minimizing pollution, and protecting the natural environment. These objectives may be constructively pursued by thorough assessment at an early stage, as part of the process of choosing the most efficient option among competing alternatives. The choice of the best development depends not only on measures of financial return, but also upon the selection of the most appropriate site to meet environmental criteria and to respect the feelings and views of residents. An eye to future expansion should also be maintained.

With the increasing complexity of economic, social and environmental impacts of building on the environment and the environmental issues considering climate change often discussed at the nation and international agenda, much attention is paid on building sustainability performance. These discussions inspired the development of tools and methods to assess building sustainability performance in order to influence how buildings are designed, constructed and used.

With the release of the Building Research Establishment Environmental Assessment Method (BREEAM) in 1990, attempts have been made to develop a comprehensive framework that encompass a broad range of environmental criteria in assessing building performance in a sustainability context. Since then building sustainability performance certification schemes have been multiplying throughout the world through drawing on the collective knowledge and experience of other systems (Cole, 2006). There are growing concerns on the effectiveness of building assessment methods as they are typically concerned with their consequences on buildings as completed products, however, more attention is now also paid to consider the impacts at various stages in the building process (Ding, 2008; Kaatz, Root, and Bowen, 2005; Shen, Wu and Wang, 2002).

The scope of this paper is intended to (1) examine the need for the integration of assessing environmental and sustainable development consideration into building process, and (2) apply this approach in building process using the Sustainable Development Value and Sustainable Development Ability to reflect on the sustainability ability on an investment.

\section{The challenges of assessing building sustainability}

Sustainability in construction is often a buzz word than an actual practice. Building environmental assessment methods were initially conceived to provide an objective evaluation of the resource use, ecological loadings, and indoor environmental quality of buildings. These environmental assessment methods were largely a framework in organising existing knowledge and experience into a practical approach for professionals to use. Therefore these assessment tools are developed to be simple to use, easy to follow and comprehensive enough to capture social and environmental criteria in a single tool. For the 
past decade these tools have made significant contribution to improve building performance towards the sustainability goal.

Nowadays almost every country or region has at least one form of environmental assessment tools to improve sustainable performance of buildings. These tools help to improve overall environmental awareness among construction professionals towards sustainable practices and achieve the goal of sustainability in the construction industry.

Environmental building assessment methods have moved beyond voluntary market place mechanism as they are now increasingly being specified as performance requirements, are being considered as potential incentives for development approval (Cole and Howard, 2005). Some countries or regions have even made environmental assessment of building projects mandatory at some stages of a development, such as BASIX in Australia and EcoHomes in the UK for residential developments, and Green Mark for all types of constructions in Singapore (Ding, 2008). They are expected to contribute in reducing environmental impacts, increasing economic viability and satisfying client's development objects.

With an increasing in importance existing environmental building assessment tools will need further improvements in order to deal with the increasing readiness of its target market for more sophisticated discourse with respect to the understanding of sustainability issues and in facilitating the integration of sustainability consideration in construction decision-making (Kaatz et al., 2006; Zimmerman and Kibert, 2007). The role and expectation for building environmental assessment tools are changing and constant improvement are needed to make it more relevant and effective. Stakeholders' participation in the assessment process is an area to be encouraged in order to respond effectively to the new challenges and requirements posed by the sustainability agenda. In other words further improvement in building sustainability assessment may be promoted as collaborative activities among building stakeholders in order to enable a vision of sustainable construction to be of value and to be realizable (Kaatz et al., 2006; Ofori and Ho, 2004; Zimmerman and Kibert, 2007).

In future development building environmental assessment methods may not be used solely to evaluate the quality of building performance but rather, it should also be used to transform the contents of methods by incorporating the principles of sustainable development directly into the building development process through information exchange and knowledge transfer. The new development will be a way to uphold balanced performance of a building towards economic, environmental and social objectives, thus influence the ways the buildings are designed, constructed, used and demolished. The structure of the building process influences the available opportunities for exploiting economics of scale and the incorporation of sustainability measures into building process are often more effective (van Burren and de Jong, 2007).

Kaatz et al. (2006) state that existing building environmental assessment tools are green building assessment methods which assess building performance against a pre-determined set of environmental criteria but the assessment methods should go beyond to address a broader set of environmental, social and economic issues. Greater emphasis should be placed on the process and transformation that occur within a building system to reflect sustainability values and principles of construction (Kaatz et al., 2006; Shen, Wu and Wang, 2002; Shen et al., 2005). Indeed building environmental assessment will need to be 
considered throughout the entire life span of a development. Through a close integration of building assessment with the building process, sustainability principles can be explicitly integrated with a building's objective and goals.

Project performance traditionally refers to the outcomes of construction cost, time and quality. According to WCED (1987) the concerns of building performance in line with the goal of sustainable development includes the sustainability criteria of economic, social and environmental development across the entire life span of a project. These three principles will have different impacts at various stages of a development. As a result it will be important and essential to assess a development to the entire building process (Shen et al. 2002, Kaatz et al. 2006). Van Paumgartten (2003) states that both economic and environmental performances of a development can be maximised through integration of sustainability into the building process. Kaatz et al. (2006) suggest the use of environmental assessment to enhance its ability to impact on the design and construction practice and to challenge the existing norms and values of those responsible for the delivery of buildings. It is beyond the current narrow technical focus and provides opportunities for a more conscious use of such method to influence the quality of a building project through the building process. So that sustainability can be integrated into the project life cycle and communicated in a structured way for a more inclusive stakeholder representation in the building process.

\section{Rationale for Sustainable Development Value (SDV) and Sustainable Development Ability (SDA)}

The initial decision to proceed with a development rests with the financial viability of the proposal. This is often expressed by forecasting project benefits received and project costs incurred in undertaking a project. The appraisal of the relationship between these two elements is an important step in decision making. The most popular techniques for assessing projects from a developer's point-of-view has been cost benefit analysis, payback periods, internal rate of return and so forth to determine profitability and long-term viability. Following a decision by the developer in respect of the desired direction of investment, the next phase is to discuss the project with the planning and pollution-control authorities. In many cases an environmental impact statement may be required and there is always the possibility of a public inquiry. The ultimate aim is to combine economic viability with environmental quality (CIB, 1999). The pursuance of sustainable development presents a challenge that sustainability of a construction project development must be assessed before its commencement. That is to assess the feasibility of a project investment by investigating into the economic ability as well as the environmental viability to determine whether a project is worth going ahead.

The impact caused by construction activities on the environment occurs throughout a project's life cycle. At the initial stage, a construction project consumes many types of environmental resources including both renewable and non-renewable resources. During the construction stage, typical environmental impacts occur from implementing a project such as air pollution, the degradation of water quality, noise pollution, generation of solid wastes. During its operation, a construction project consumes a vast amount of energy and natural resources. At the end of a construction project's life cycle, the demolition activities generate a large volume of construction wastes. The assessment of various impacts from construction activities on the environment during the building process shows potential of making significant contribution to protecting the environment and attainting sustainable development by properly implementing a construction project (Shen et al., 2005). 
Furthermore, environmental impacts vary greatly at different stages of a construction project. However, it appears that there is no existing integration of assessing building sustainability at various stages of a building process. Kaatz et al. (2006) state that if building sustainability assessment is to transform the quality of construction practice positively, it has to be closely integrated with the building process. In considering the importance of assessing a project's viability and integrating the assessment of sustainability in the building process, the models of Sustainable Development Value (SDV) and Sustainable Development Ability (SDA) are developed to fill the gap.

SDV of a construction project is the value attributable to building project that reflects the attainment of sustainable development principles in the design, construction and operation of built projects. As derived from the literature, the major principle of sustainable development is a three-dimensional aspects, namely economic (E), social (S) and environmental (En) (Kaatz et al., 2006; Ny et al., 2006;Du Plessis, 2007; Nelms, Russell and Lence, 2007; Ding, 2008). The three pillar model of sustainable development was first introduced in 1987 (Barbier, 1987) which has formed the basis of almost every subsequent framework (de Plessis, 2007).

Based on this principle, the three dimensions are variables that affect the level of contribution from a construction project viewpoint to the attainment of sustainable development. Therefore, SDV can be used to indicate the significance of developing a construction project to the attainment of the three dimensions of sustainable development. As such the model of SDV can be presented as:

$\mathrm{SDV}=f\{\mathrm{Ec}, \mathrm{En}, \mathrm{Ev}\}$

Where SDV = Sustainable Development Value

$E_{c}=$ the significance of a project to sustainable economic development

$\mathrm{En}=$ the significance of a project to sustainable energy development

$\mathrm{Ev}=$ the significance of a project to sustainable environmental development

The measure of SDV is a function of time and specifies a specific value at a specific time. While it may be impossible to allow a project having positive contributions all the time during its life cycle, it is the objective of developing an adequate project to ensure that the total contribution during its life cycle is positive. In other words SDV can be positive or negative at a specific time, but the total value of SDV during the whole life cycle must be positive. A development with positive total value of SDV can be considered feasible or adequate in line with the sustainable development principle. This conception requests that the assessment on the feasibility of developing a construction project should be undertaken from the viewpoints of economic, social and environmental perspectives throughout project life cycle. The application of this conception pursues the maximum totality of SDV.

Whilst there are infinite numbers of specific time points across a building life cycle process, there are five typical stages which effectively address the process, including inception, construction, commissioning, operation and demolition. Therefore SDV is measured for the five stages. In other words, it is a step function which assumes different values at different stages of a project life process. This step function can be written in model (2): 


$$
S D V=\left\{\begin{array}{l}
S D V_{I}=f\left\{E c_{I}, E n_{I}, E v_{I}\right\}(t=\text { inception }) \\
S D V_{C}=f\left\{E c_{C}, E n_{C}, E v_{C}\right\}(t=\text { construction }) \\
S D V_{C o}=f\left\{E c_{C o}, E n_{C o}, E v_{C o}\right\}(t=\text { commissioning }) \\
S D V_{O}=f\left\{E c_{O}, E n_{O}, E v_{O}\right\}(t=\text { operation }) \\
S D V_{D}=f\left\{E c_{D}, E n_{D}, E v_{D}\right\}(t=\text { demolition })
\end{array}\right\}
$$

Where SDV = Sustainable Development Value

$\mathrm{SDV}_{\mathrm{I}}=$ Sustainable development value at inception stage

$\mathrm{SDV}_{\mathrm{C}}=$ Sustainable development value at construction stage

$\mathrm{SDV}_{\mathrm{Co}_{0}}=$ Sustainable development value at commissioning stage

$\mathrm{SDV}_{\mathrm{O}}=$ Sustainable development value at operation stage

$\mathrm{SDV}_{\mathrm{D}}=$ Sustainable development value at demolition stage

For example, the SDV at inception stage is denoted as:

$\mathrm{SDV}_{\mathrm{I}}=f\left\{\mathrm{Ec}_{\mathrm{I}}, \mathrm{En}_{\mathrm{I}}, \mathrm{Ev}_{\mathrm{I}}\right\}$

Where $E c_{I}=$ Economic criterion at inception stage

$\mathrm{En}_{\mathrm{I}}=$ Social criterion at inception stage

$\mathrm{Ev}_{\mathrm{I}}=$ Environmental criterion at inception stage

Similar models will be presented for $\mathrm{SDV}$ at the construction $\left(\mathrm{SDV}_{\mathrm{C}}\right)$, commissioning $\left(\mathrm{SDV}_{\mathrm{Co}}\right)$, operation $\left(\mathrm{SDV}_{\mathrm{O}}\right)$ and demolition $\left(\mathrm{SDV}_{\mathrm{D}}\right)$ stages of a project.

The totality of SDV during the life cycle of a construction project is defined as an ability that the project will have in contributing to the attainment of sustainable development, and such ability is called as Sustainability Development Ability (SDA). Therefore SDA can be presented as:

$$
S D A=\int_{\text {LifeCycle }} f\left\{S D V_{I}, S D V_{C}, \mathrm{SDV}_{\mathrm{Co}}, \mathrm{SDV}_{\mathrm{O}}, \mathrm{SDV}_{\mathrm{D}}\right\}
$$

In the above models (2) and (3), the value of SDV at various stages is determined by multidimensional attributes, namely, economic, social and environmental criteria. The factors underpinning the three pillars are examined through investigating the sub-criteria using an analytical hierarchy process (AHP) technique. The conception of model (3) can be elaborated as a decision hierarchy, as shown in Figure 1, which breaks the development process (level one) down in various levels of hierarchy criteria. Level two shows the three criteria to meet the project objectives, level three lists the sub-criteria under the respective criterion in level two. There can be more levels in this decision hierarchy. At the bottom level of the hierarchy, values should be assigned in terms of economic, environmental and social performance, which enable to derive calculations.

For example, the analysis to the value of $\mathrm{E}_{\mathrm{I}}$, economic sustainability at inception stage can be given as follows:

$$
E_{I}=\sum_{i=1}^{n} E c_{I}^{i} W_{i}
$$

where $E_{I}=$ the performance of economic sustainability criteria at inception stage

$\mathrm{Ec}_{\mathrm{I}}{ }^{i}=$ the performance of economic sustainability criteria for sub-criteria $i$ (where $\mathrm{i}$ $=1,2, \ldots n)$

$\mathrm{W}_{i}=$ Weight of criterion for sub-criteria $i$ 
Similar analysis can be given to other variables in model (2) and (3).

Figure 1 Hierarchical model for measuring SDA and SDV

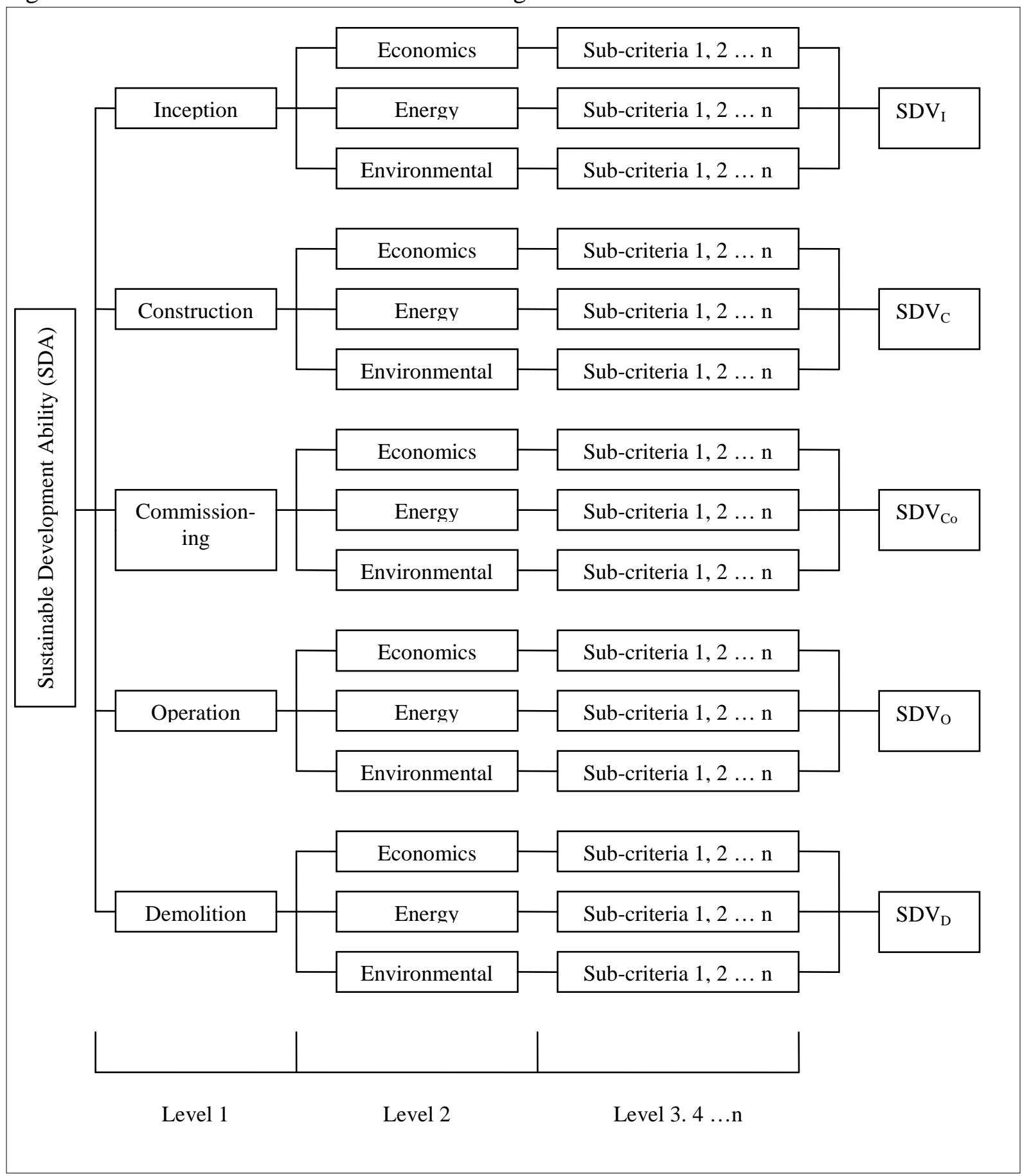

In the hierarchical model, prioritization of criteria will be undertaken to determine the relative weights of various criteria of the hierarchy in each level. Each criterion in each level is compared pairwise in terms of their importance to the criteria in the next higher level. Starting at the top of the hierarchy and working down, a number of pairwise comparison matrices are created in the process of comparing criteria at a given level. The weights can be derived either by the decision-makers' own preferences or together with 
other people participating in the decision making process such as those people who are likely to be affected by the development. The weights are determined in terms of verbal scale as recommended by Saaty (1980). They can be expressed as equally important, moderately more important, strongly more important, very strongly more important and extremely more important. These preferences can be converted into numerical values of 1 , 3, 5, 7 and 9 respectively while 2, 4, 6, and 8 are intermediate values for compromises between two successive qualitative judgments. The scale of 1 to 10 is reasonable and sufficient to reflect the extent of importance among criteria. The three criteria at level two are ranked according to their relative importance towards the development objective. By following this analytical process, weight values for all criteria will be established.

\section{$4 \quad$ Model implementation}

The models of SDA and SDV have been applied to assess sustainability of a project by the entire project life cycle. The project was an industrial building used for a workshop and show room in Newcastle, New South Wales of Australia. The project has three design options. Option A is a single-level warehouse with a two-storey office area constructed by structural steel portal frame with Colorbond metal sheeting for the walls and roof decking. Option B is a single-level design for both warehouse and office area and is constructed by precast concrete panels with painted finish on the outside, metal roof decking on steel trusses. Option $\mathrm{C}$ is a two-storey design for both the warehouse and office and is constructed using reinforced concrete beams and columns with face brickwork.

Sustainability performance of each design was undertaken to reveal the best option on a life cycle approach. The assessment of each design was broken down into the five stages of the life cycle, namely inception, construction, commissioning, operation and demolition stages (Shen, Wu and Wang, 2002). In considering that inception and commissioning stages are usually short and also to simplify the assessment process in this case study, the sustainability assessment at the inception stage was combined with construction stage, whilst commissioning was combined with operation stage. Therefore the assessment for each design is now the construction, operation and demolition stages.

The three criteria: namely economics, energy and environmental, have been assessed and presented in Table 1. In assessing the economic criterion both costs and benefits were measured in terms of rental return and recycling of salvage materials respectively at the operation and demolition stages and BCR was calculated accordingly. However at the construction stage only costs were incurred, therefore the BCR was calculated based on the least cost approach as the cost spent on the construction work could be used as an opportunity cost in another investment. The discounted cash flow approach is used to bring costs and benefits into an equivalent monetary value so that the overall net benefit of the three options can be calculated and compared over a 40-year economic life span at a discount rate of $5 \%$. From the table Option B demonstrates the highest BCR at the construction and operation stage whilst option $\mathrm{A}$ is the best at the demolition stage.

The energy criterion was assessed based on a whole-of-life approach where both initial and recurrent embodied energy were estimated in addition to the energy used during operation and demolition. The energy estimated at the construction stage includes embodied energy in the materials for the building and the energy used during on-site process. The energy used during operation stage includes recurrent embodied energy used during maintenance/repair and the energy used in the manufacturing of fixtures and fittings. There is no data on operation energy consumption of this building type. The operation energy has 
therefore been derived from the energy bills of existing industrial buildings in the same area and extended to cover a 40-year economic life span. From the table Option B demonstrates the lowest energy consumption throughout the entire three stages and followed by Option C.

Table 1 summarises the assessment details for each design.

\begin{tabular}{|c|c|c|c|}
\hline Option & A & B & $\mathbf{C}$ \\
\hline GFA $\left(\mathrm{m}^{2}\right)$ & 850 & 1,700 & 1,300 \\
\hline \multicolumn{4}{|l|}{ Construction Stage } \\
\hline \multicolumn{4}{|l|}{ Economics } \\
\hline$-\operatorname{Costs}\left(\$ / \mathrm{m}^{2}\right)$ & 1,300 & 600 & 800 \\
\hline - Benefit cost ratio (BCR) & 0.5 & 1.0 & 0.8 \\
\hline Energy $\left(\mathrm{GJ} / \mathrm{m}^{2}\right)$ & 5.9 & 3.5 & 5.4 \\
\hline $\begin{array}{l}\text { Environmental (Score) } \\
\quad \text { - Social benefits }(\max \text { score }=105) \\
\quad \text { - Environmental risk }(\max \text { score }=320)\end{array}$ & $\begin{array}{c}42 \\
170 \\
\end{array}$ & $\begin{array}{c}38 \\
165 \\
\end{array}$ & $\begin{array}{c}41 \\
160 \\
\end{array}$ \\
\hline \multicolumn{4}{|l|}{ Operation Stage } \\
\hline \multicolumn{4}{|l|}{ Economics } \\
\hline$-\operatorname{Costs}\left(\$ / \mathrm{m}^{2}\right)$ & 920 & 600 & 700 \\
\hline - Benefits $\left(\$ / m^{2}\right)$ & 3200 & 3300 & 3100 \\
\hline - Benefit cost ratio (BCR) & 3.5 & 5.5 & 4.4 \\
\hline Energy $\left(\mathrm{GJ} / \mathrm{m}^{2}\right)$ & 18.8 & 9.7 & 13.1 \\
\hline $\begin{array}{l}\text { Environmental (Score) } \\
\text { - } \text { Social benefits }(\max \text { score }=290) \\
\text { - } \text { Environmental risk }(\text { max score }=35)\end{array}$ & $\begin{array}{c}141 \\
18\end{array}$ & $\begin{array}{c}150 \\
17\end{array}$ & $\begin{array}{c}161 \\
14\end{array}$ \\
\hline \multicolumn{4}{|l|}{ Demolition Stage } \\
\hline \multicolumn{4}{|l|}{ Economics } \\
\hline - Costs $\left(\$ / \mathrm{m}^{2}\right)$ & 75 & 62 & 65 \\
\hline - Benefits $\left(\$ / \mathrm{m}^{2}\right)$ & 70 & 47 & 43 \\
\hline - Benefit cost ratio (BCR) & 0.9 & 0.8 & 0.7 \\
\hline Energy $\left(\mathrm{GJ} / \mathrm{m}^{2}\right)$ & 0.12 & 0.07 & 0.11 \\
\hline $\begin{array}{l}\text { Environmental (Score) } \\
\text { - } \text { Social benefits }(\max \text { score }=20) \\
\text { - } \text { Environmental risk }(\max \text { score }=35)\end{array}$ & $\begin{array}{l}12 \\
16\end{array}$ & $\begin{array}{c}9 \\
17\end{array}$ & $\begin{array}{c}8 \\
16 \\
\end{array}$ \\
\hline
\end{tabular}

Environmental criterion was evaluated using a multi-criteria approach (Ding 2005). Seven members of the development's design team evaluated the project. In social benefits the three options were evaluated against seven criteria and each criterion was further broken down into two to five sub-criteria at a total of 20 sub-criteria. In terms of environmental risk the three options were assessed against five criteria which were broken down into a total 26 sub-criteria. A scale of 1-5 was used to express the level of benefits of the development's design team, consisting of an architect, a quantity surveyor, a contractor, an engineer, a project manager and two representatives from the clients. The sub-criteria for both social benefits and environmental risk were split among the three stages of the development and the maximum scores at each stage were included in Table 1 . From the table option A demonstrates the maximum social benefits whiles Option $\mathrm{C}$ demonstrates the minimum environmental risk for both operation and demolition stages. 
Standardisation was processed to the data in Table 1 in order to undertake comparison. Table 2 presents the two-dimensional evaluation matrix for the three criteria as in the rows, whilst the three design alternatives are in the columns. The weights for the three sustainability performance criteria were derived as described above. Since the three criteria were in different measurement units they were standardised before being multiplied with the weights. The SDV is the function of the three criteria at each stage based on the formulae 1 and 2 presented above. It is calculated for each option by multiplying each value by the weight, followed by summing the weighted scores for all criteria using the weighted summation method. The value of SDA is calculated as the function of SDV at various stages as in formula 3 and therefore the SDA for the three options are 15.12, 19.37 and 16.69 for options A, B and C respectively. In respect to the principle of SDA option B demonstrates the best option overall even though the option A has a better SDV value at the demolition stage. The performance of option $\mathrm{B}$ at the demolition stage can be improved by adopting a more advanced technology in the techniques of demolition as well as developing more opportunities for recycling salvage materials for precast concrete construction.

Table 2 Two-dimensional evaluation matrix (after standardisation)

\begin{tabular}{|c|c|c|c|c|c|}
\hline \multirow{2}{*}{ Criteria } & \multicolumn{3}{|c|}{ Option } & \multirow[t]{2}{*}{ Weights } & \multirow{2}{*}{ Remarks } \\
\hline & A & B & $\mathbf{C}$ & & \\
\hline \multicolumn{6}{|l|}{ Construction Stage } \\
\hline Economics (BCR) & 0.46 & 1.00 & 0.79 & 3.0 & The higher the better \\
\hline Energy consumption & 1.00 & 0.60 & 0.92 & 2.5 & The lower the better \\
\hline $\begin{array}{l}\text { Environmental } \\
\text { - } \quad \text { Social benefits } \\
\text { - } \quad \text { Environmental risk }\end{array}$ & $\begin{array}{l}1.02 \\
1.03\end{array}$ & $\begin{array}{l}0.93 \\
1.00\end{array}$ & $\begin{array}{l}1.00 \\
0.97\end{array}$ & $\begin{array}{l}2.4 \\
2.1\end{array}$ & $\begin{array}{l}\text { The higher the better } \\
\text { The lower the better }\end{array}$ \\
\hline $\mathrm{SDV}_{\mathrm{C}}$ & 3.77 & 6.22 & 5.04 & & The higher the better \\
\hline \multicolumn{6}{|l|}{ Operation Stage } \\
\hline Economics (BCR) & 0.64 & 1.00 & 0.84 & 3.0 & The higher the better \\
\hline Energy consumption & 1.00 & 0.52 & 0.69 & 2.5 & The lower the better \\
\hline $\begin{array}{l}\text { Environmental } \\
\text { - } \quad \text { Social benefits } \\
\text { - } \quad \text { Environmental risk }\end{array}$ & $\begin{array}{l}0.88 \\
1.06\end{array}$ & $\begin{array}{l}0.93 \\
1.00\end{array}$ & $\begin{array}{l}1.00 \\
0.82\end{array}$ & $\begin{array}{l}2.4 \\
2.1\end{array}$ & $\begin{array}{l}\text { The higher the better } \\
\text { The lower the better }\end{array}$ \\
\hline $\mathrm{SDV}_{\mathrm{O}}$ & 3.90 & 6.45 & 6.06 & & The higher the better \\
\hline \multicolumn{6}{|l|}{ Demolition Stage } \\
\hline Economics (BCR) & 1.24 & 1.00 & 0.95 & 3.0 & The higher the better \\
\hline Energy consumption & 1.00 & 0.60 & 0.92 & 2.5 & The lower the better \\
\hline $\begin{array}{l}\text { Environmental } \\
\text { - } \quad \text { Social benefits } \\
\text { - } \quad \text { Environmental risk }\end{array}$ & $\begin{array}{l}1.50 \\
0.94\end{array}$ & $\begin{array}{l}1.13 \\
1.00\end{array}$ & $\begin{array}{l}1.00 \\
0.94\end{array}$ & $\begin{array}{l}2.4 \\
2.1\end{array}$ & $\begin{array}{l}\text { The higher the better } \\
\text { The lower the better }\end{array}$ \\
\hline SDV $_{D}$ & 7.45 & 6.70 & 5.59 & & The higher the better \\
\hline
\end{tabular}

\section{$5 \quad$ Conclusion}

Whilst construction activities have been contributing to the development of modern societies, they are also contributing adverse effects on the natural and man-made environment. Traditional construction practices assess the viability of a built project mainly using economic feasibility. This paper reveals that proper development consideration at an outset can make a significant contribution to achieving better sustainability particularly the 
goal of ecologically sustainable development. Most of the existing environmental performance assessment approaches assess the overall performance of a project but do not take into consideration the impact that may have at various stages across a building's life cycle. In achieving the goal of advancing sustainability performance of building practices, building sustainability assessment should be integrated into the building process. The models of SDV and SDA in this paper are developed and presented to fill the gap. The paper presents an alternative approach for assessing the feasibility of a built project during its life cycle in attaining the sustainable development principle. Based on the modelling principles, the judgement can be made to whether or not the development of a built project is in line with sustainable development principles and improvement can be made accordingly. The case study demonstrates the applicability of assessing sustainability performance by measuring the SDA at various stages of the building process that combines objective measures with subjective measures into a single tool to analyse the best option among alternatives. The SDA model offers opportunity to reveal the sustainability performance at various stages of a development so that resources can be focused on the stage that has the significant impacts for improvement. This way time, cost and resources can be utilised more efficiently and effectively.

The procedures for applying the SDA prototype model have been formulated and their effectiveness has been demonstrated by applying into a case study. From the case study, it was learnt that when different weightings for the three sustainable development determinants are applied, the sustainability attainment between different alternative project plans is different. This study provides an approach to assessing a construction project's sustainability, which can be used as reference for further study into improving the sustainability of construction projects.

\section{References}

Barbier, E.B. (1987) 'The concept of sustainable economic development', Environmental Conservation, Vol. 14, No. 2, pp.101-110.

CIB (1999) Agenda on sustainable construction, CIB Report Publications, USA, pp.41-43.

Cole, R.J. \& Howard, N. (2005) 'Building environmental assessment tools: current and future roles', Paper Presented at the 2005 World Sustainable Building Conference in Tokyo, 27-29 September through the Internet: http://www.sb05.com/homeE.html. [accessed 25/2/2008].

Cole, R.J. (2006) 'Shared markets: coexisting building environmental assessment methods', Building Research \& Information, Vol. 34, No. 4, pp. 357-371.

Ding, G.K.C. (2005) 'Developing a multicriteria approach for the measurement of sustainable performance’, Building Research \& Information, Vol. 33, No. 1, p 3-16.

Ding, G.K.C. (2008) 'Sustainable construction - the role of environmental assessment tools’, Journal of Environmental Management, Vol. 86, No. 3, p 451-464.

Du Plessis, C. (2007) 'A strategic framework for sustainable construction in developing countries’, Construction Management \& Economics, January, Vol. 25, pp. 67-76.

Kaatz, E., Root, D. \& Bowen, P. (2005) 'Broadening project participation through a modified building sustainability assessment', Building Research \& Information, Vol. 33, No. 5, pp. 441-454. 
Kaatz, E., Root, D.S., Bowen, P.A. \& Hill, R.C. (2006) 'Advancing key outcomes of sustainability building assessment’, Building Research \& Information, Vol. 34, No. 4, pp. 308-320.

Nelms, C.E., Russell, A.D. \& Lence, B.J. (2007) 'Assessing the performance of sustainable technologies: a framework and its application’, Building Research \& Information, Vol. 35, No. 3, pp.237-251.

Ny, H., MacDonald, J.P., Broman, G., Yamamoto, R. \& Robert, K.H. (2006) 'Sustainability constraints as system boundaries', Journal of Industrial Ecology, Vol. 10, No. 1/2, pp. 61-77.

Ofori, G. \& Ho, K.K. (2004) 'Translating Singapore architects' environmental awareness into decision making', Building Research \& Information, Jan/Feb., Vol. 34, No. 1, pp.27-37.

Saaty, T.L. (1980) The Analytic Hierarchy Process, McGraw-Hill.

Shen, L.Y., Wu, M. \& Wang, J.Y. (2002) 'A model for assessing the feasibility of construction project in contributing to the attainment of sustainable development', Journal of Construction Research, Vol. 3, No. 2, pp. 255-269.

Shen, L.Y., Wu, Y.Z., Chan, E.H.W. \& Hao, J.L. (2005) 'Application of system dynamics for assessment of sustainable performance of construction projects', Journal of Zhejiang University Science, Vol. 6A, Issue 4, pp. 339-349.

UNEP SBCI (2008). United Nations Environment Programme - Sustainable Building \& Construction Initiative through Internet: Http://earthtrends.wri.org/updates/node/232 [accessed 26/2/09].

Van Bueren, E. \& De Jong, J. (207) 'Establishing sustainability: policy successes and failures’, Building Research \& Information, Vol. 35, No 5, pp.543-556.

Von Paumgartten, P. (2003) 'The business case for high-performance green buildings: sustainability and its financial impact', Journal of Facilities Management, Vol. 2, No. 1, pp.26-34.

World Commission on Environment and Development (1987) Our common future, Oxford University.

Zimmerman, A. \& Kibert, C.J. (2007) 'Informing LEED's next generation with the natural step’, Building Research \& Information, Vol. 35, No. 6, pp. 681-689. 